\title{
Understanding How Social Media Is Influencing the Way People Communicate: Verbally and Written
}

\author{
Noelle Defede ${ }^{1}$, Nina Marie Magdaraog ${ }^{1}$, Sakshi Chiragbhai Thakkar ${ }^{1} \&$ Gulhan Bizel $^{1}$ \\ ${ }^{1}$ School of Business, Saint Peter's University, Jersey City, New Jersey, USA \\ Correspondence: Gulhan Bizel, School of Business, Saint Peter's University, Jersey City, New Jersey, USA.
}

Received: February 2, 2021 Accepted: March 9, 2021 Online Published: March 28, 2021

doi:10.5539/ijms.v13n2p1 URL: https://doi.org/10.5539/ijms.v13n2p1

\begin{abstract}
The way in which people communicate has changed significantly in the past decade. For instance, instead of reading newspapers to find out the latest news many flock to Twitter ${ }^{\mathrm{TM}}$ to see what is trending for the day. Communication online via social media has changed the way people view many things. Therefore, with this understanding, it is notable to understand how social media is influencing the way people communicate: verbally and written. This paper dives more into finding more descriptive explanations of how it does so, such as whether they have changed the way they speak in person and online or the way they type their emails and texts. Using methods that involve secondary sources such as research journals and articles as well as conducting a survey questionnaire composed of participants from the United States and India is reflected in this paper. The research findings indicate that social media does influence the way people communicate because of how it allows people to gain more knowledge and information, it has become more accessible for others and it fuels conversion in terms of using emoticons. This research paper reflects the change that social media has brought forth to interpersonal communication.
\end{abstract}

Keywords: interpersonal communication, social media changes, social media influence

\section{Introduction Embedded with Literature Review}

The use of social media has risen dramatically in the 21 st century. It is evident and important to realize how social media has become an integral part of a person's daily life. The increased normality of communicating through social media has directly affected how human beings interact with one another, and because of this increase it has prompted this research study to understand how it has done so. Social media has made an opportunity for individuals to collaborate in a useful and fundamental manner to propel individuals socially. Furthermore, "social media provides awareness among society like campaigns, advertisement articles, promotions which helps the society to be up to date with the current information" (Siddiqui \& Singh, 2016). However, there are also negative aspects of social media and its influence on communication. Some include "lack of privacy", "communication overload", and "technology addiction" (Subramanian, 2017). With this in mind, it should be taken into consideration how social media has become a great influence on interpersonal communication. A previous research journal conducted a study for this topic in 2015, called "Impact Of Social Media On Interpersonal Communication Patterns" by Velga Vevere. This research paper was prompted to build on Vevere's research journal to gain an updated understanding of social media's influence. The paper ventures into this topic and collects significant data in order to understand various perspectives from participants to gain a better idea of how social media has such a great influence on the way people communicate both verbally and written.

\subsection{Social Media Changes on Interpersonal Communication}

Social media platforms "have created a phenomenon on the internet that has gained popularity over the last decade" (Sponcil \& Gitimu, 2012). The change it has brought forth has "exploded as a category of online discourse where people create content, share it, bookmark it and network at a prodigious rate" (Owusu-Acheaw \& Larson, 2015). This greatly explains how online users share and connect with others online to gain more insight on a topic or subject that he or she may be interested in learning more about. Opinions can be shared through online reviews and forums and communicating with one another has never been simpler. With social media, "communication occurred when someone is responding or commenting on others status or initiating conversation with someone else. Since the boom of social media, the online communication has taken over some of people's communication" (Othman, Fariha, \& Ngah, 2016). Therefore, with this in mind, interpersonal communication has changed in more 
ways than one because of the influence of social media.

Some major areas of change have occurred in the following (Social media effects on communication, 2020):

1) Exposure to messages

2) Self-expressions

3) Communication styles

4) Businesses

As interpersonal communication deals with verbal and non-verbal cues such as facial expressions and body language, it is interesting to notice the change with the exposure to messages and self-expressions. Exposure to messages deals with how much information a person is consuming when looking at social media feeds. Many people will scroll endlessly and forget the world around them. Therefore, causing people to be less engaged with those around them. A person may be eating dinner with their family but will have their phone in their hand to look at their Twitter ${ }^{\mathrm{TM}}$ feed instead of speaking to those sitting at the table with them. For self-expressions, there is a "sense of urgency", "need to share" (Social media effects on communication, 2020), and a need to interact with others online especially when it comes to social media posts. For instance, "excessive use of social media for connecting with 'the other' reduces empathy among the people as they indulge in static and unidirectional conversations. For example, Misra et al. (2014) observed that people who had conversations in the absence of mobile devices demonstrated higher levels of empathic concerns as compared to those who were carrying their conversation along with mobile devices as props" (Jha \& Srirang, 2020). With this understanding, it greatly explains how social media has influenced communication.

Communication styles have drastically taken a 360-degree turn because of the way in which people speak or type has changed. For instance, "the social web has changed the written word in a couple of crucial ways: Writing is more summarized: However, this has allowed for shorter sentences or paragraphs and made way for neglecting correct grammar use" (Subramanian, 2017). Abbreviations are more notable than ever when speaking or texting another person. For example, words such as OMG, TTYL, and LOL are some of the ways in which words have been shortened for easier use during instant messaging. Furthermore, "people who communicate via social media or text message aren't necessarily spelling things incorrectly; they are speaking a new language entirely (Subramanian, 2017). With this new language, it showcases the change in communication because of the way in which social media has influenced it. Nowadays, many teens are using GIFs and various emojis to express their feelings and emotions to their friends and families. From the heart emoji to show love to the skull emoji to show how a person has died from laughing too much, it is amazing to understand the way in which people use emojis to communicate. Viral messages are also a change in communication style as currently many teens use Tik Tok and learn different funny phrases and terms that are then used in their text messages or social media posts.

As for businesses, the change of medium from newspapers, television, and radio to the use of social media has made it easier and simpler to promote various products. Social media has garnered a way to influence buying choices for many people as well. For instance, "social media is transforming the way organizations communicate - the many social tools that are available today are very cost-effective compared to traditional approaches such as email and online advertising. Blog posts and tweets enable businesses to create communities, offer immediate feedback or assistance, and promote their products and services" (Baruah, 2012). Furthermore, "the increasing popularity of social sites like Twitter, Facebook and LinkedIn, social networks have gained attention as the most viable communication choice for the bloggers, article writers, and content creators" (Subramanian, 2017). With this in mind, it showcases a change in how social media has even influenced communication for businesses as well.

\section{Research Methodology}

The research objective is to understand how social media can influence the way people communicate with each other. Therefore, the methodology is the approach utilized in order to find the answer to the question how social media affects the way people communicate. Utilizing a survey and collecting the responses allowed a conclusion to be drawn from the posed question. An analysis of these responses gave insight to patterns of social media use as well as people's perceptions of the consequences of it.

\subsection{Research Method}

There are two types of research methods, which are qualitative and quantitative research. For this research project, both methods were used to conduct the overall study. Qualitative research is "designed to uncover consumer attitudes, beliefs and opinions rather than facts," while quantitative research "uses mathematical analysis to 
provide proof of a fact or hypothesis" (Kolb, 2018). However, the survey was sent to family and friends from the United States and India, which included multiple-choice questions and three open-ended questions to gain the opinions and perspectives of those who completed the questionnaire. The survey takes a qualitative approach since the open-ended questions garnered more insight and information about social media and its influence on communication. Therefore, use of any statistical software package like SPSS or STATA or EPI was not needed for the overall research.

\subsection{Sampling Procedures}

There are various sampling methods for research projects. However, for this research project, the primary sampling method to be used is a non-probability sampling method which is convenience sampling. Convenience sampling "includes the individuals who happen to be most accessible to the researcher" (Sampling methods|Types and techniques explained, 2020). It is a quicker and cheaper way to gather data however, there is a limitation to this type of sampling. The limitation to this type of sampling is that it is difficult to gather data for the overall population. It only gathers data for a portion of people and not the entire general public. Convenience sampling "can't product generalizable results" (Sampling methods|Types and techniques explained, 2020). However, for the purposes of this project, the use of convenience sampling is beneficial to gather data from friends and family from both the United States and India.

\subsubsection{Sample Size}

The sample size was calculated by sending out the survey to our friends and family as well as sharing it on social media outlets. Participants were also encouraged to send out the survey and promote it as well. The survey was kept open for 18 days and in that time period the response rate of the survey was 204 responses. Further explanation of the survey is explained in the research design part of the paper.

\subsection{Research Design-Survey}

The survey that was conducted in this project focused on the question of how social media is influencing the way people communicate. The survey was broken into two sections, which can be found in Appendix A. The survey includes demographics and social media focused questions and had a total of sixteen questions. There were six social media survey questions that were adapted from a research journal called "Impact Of Social Media On Interpersonal Communication Patterns" by Velga Vevere. The six questions used are questions 2 to 7, as shown in Appendix A. This was used to help create validity for the survey and understand if there were any similarities or differences in responses. The survey was shared on January 8th, 2021, and was closed on January 26th, 2021. The questionnaire was sent to family and friends from the United States and India and was conducted using Google Forms. Moreover, it was asked of them to send it to their family and friends in order to gain more participants for the survey. Additionally, the survey was promoted on various social media platforms such as Facebook and Instagram to gain more traction. The ethical conduct for the survey was ensured as all answers were completely anonymous and participants were informed about this before taking the survey. The participants' answers will be explained in the results section of this paper.

\section{Results}

The survey was able to attain a total of 204 participants. Table 1 showcases the demographics of the survey respondents and the number of participants as well as the overall percentage. The majority of the participants were female, with a total participation of 132 females to 68 males. Many of those, 101 respondents, that answered the survey were ages 21 to 25 . The majority of the survey takers were Asians with $77.9 \%$. While surprisingly the survey received $48 \%$ of responses from the United States and $48 \%$ from India. Lastly, data on education projects showed that the majority of the 109 participants were in their Bachelor's with 53.4\% followed by Master's degree education with $22.5 \%$. With this in mind, the results conducted from the survey garnered a better understanding of how social media has influenced the way people communicate. 


\subsection{Demographics}

Table 1. Demographics

\begin{tabular}{llll}
\hline Demographics & Categories & Participants (n) & Percentage (\%) \\
\hline Gender & Female & 132 & 64.7 \\
& Male & 68 & 33.3 \\
Age & Prefer not to say & 4 & 2 \\
& $15-20$ & 32 & 15.7 \\
& $21-25$ & 101 & 49.5 \\
& $26-30$ & 26 & 12.7 \\
Ethnicity & $31-35$ & 9 & 4.4 \\
& $36+$ & 36 & 17.6 \\
& Asian & 159 & 77.9 \\
& Black or Afircan American & 6 & 2.9 \\
& Native American or Alaskan Native & 1 & 0.5 \\
& White or Caucasian & 15 & 7.4 \\
& Native Hawaiian or Pacific Islander & 3 & 1.5 \\
& Hispanic or Latino & 15 & 7.4 \\
Education & Prefer not to say & 5 & 2.5 \\
& High school & 14 & 6.9 \\
& Bachelor's Degree & 109 & 53.4 \\
& Master's Degree & 46 & 22.5 \\
& Doctorate Degree & 6 & 2.9 \\
& Other & 29 & 14.2 \\
\hline
\end{tabular}

\subsection{Survey Multiple Choice Questions}

The following survey results showcase figures, tables, and explanations about the survey questions that were asked about how social media influences the way people communicate. It also further explains the survey findings that were sent to friends and family over the span of three weeks.

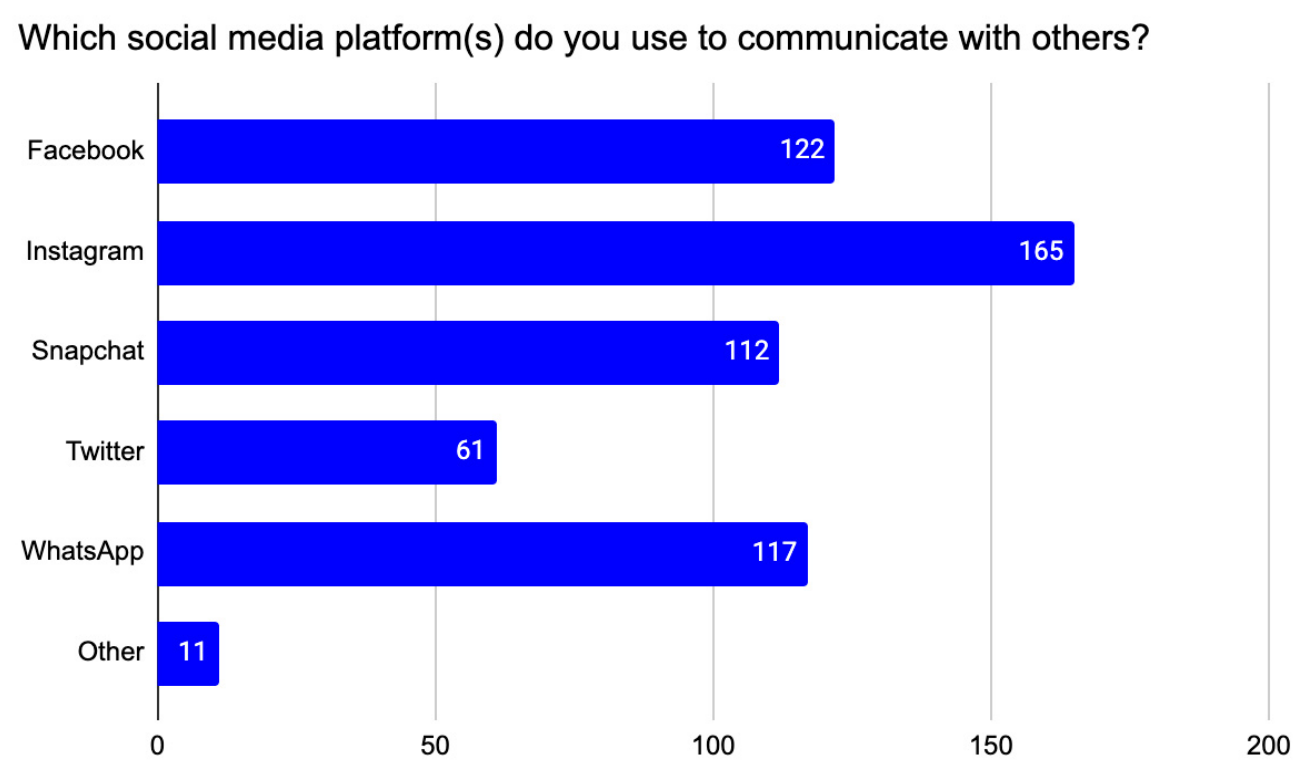

Figure 1. Which social media platform(s) do you use to communicate with others?

Figure 1 projects shows how Instagram ${ }^{\mathrm{TM}}$ is the most popular platform with $81.3 \%$ i.e., 165 participants used to communicate with others is expected since many people today post pictures and send each other direct messages 
on it to show others how they are doing. Facebook followed second with $60.1 \%$ of the votes (122 participants). WhatsApp was third with $57.6 \%$ of the responses (117 participants). Snapchat ${ }^{\mathrm{TM}}$ was fourth with $55.2 \%$ of the votes (112 responses). Twitter ${ }^{\mathrm{TM}}$ was fifth with $30 \%$ of the votes (61 participants). While the last option, other, received only 11 participants. This choice includes other social media applications such as Skype ${ }^{\mathrm{TM}}$, Tik Tok ${ }^{\mathrm{TM}}$,

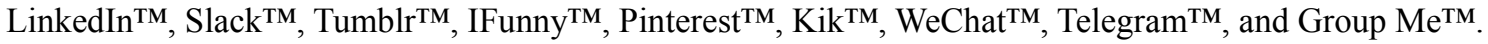

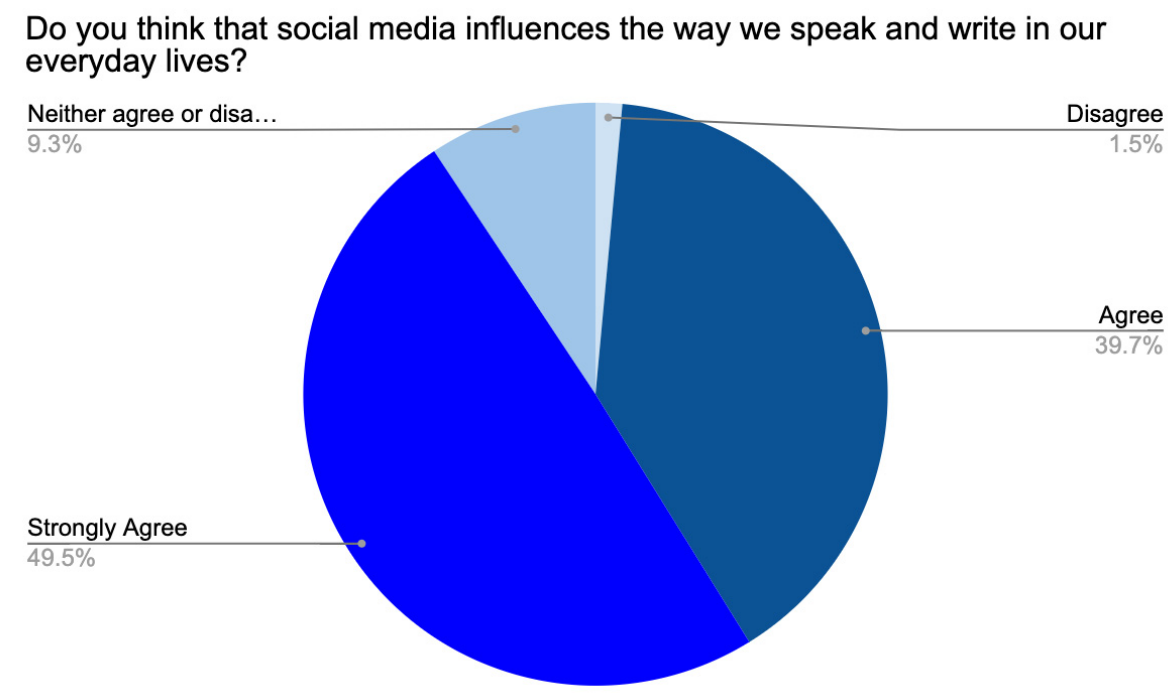

Figure 2. Do you think that social media influences the way we speak and write in our everyday lives?

Figure 2 reflects that the majority of people can strongly agree with social media having a great influence on the way people speak and write in their everyday lives. The largest percentage, 49.5\% (101 participants; 49 from the United States, 51 from India, 1 from other), strongly agreed. 39.7\% (81 participants) agreed with this statement (41participants from the United States, 33 in India, 7 from others) while only 1.5\% (3 participants all from the United States) disagreed with it. And lastly, 9.3\% (19 people; 14 from India, 5 from the United States) neither agree nor disagreed.

Table 2. Yes or no multiple-choice answers

\begin{tabular}{lll}
\hline & Yes & No \\
\hline Do you use emojis or other inserts when writing text messages or direct messages? & 185 & 19 \\
When text messaging do you think of the grammar rules and punctuation? & 152 & 52 \\
Do you post personal information on social media? & 78 & 126 \\
Whether social media is a majou form of communication tool? & 192 & 12 \\
\hline
\end{tabular}

Table 2 showcases all yes or no responses for the social media questions. The first question asked if participants used emojis when writing text messages or direct messages, it was overwhelmingly answered yes by $90.7 \%$ of the votes, this makes up the answer for 185 participants (88 from the United States, 89 from India, 8 from other). Knowing how easy it is to use an emoji or other inserts such as a GIF or photo, it is no surprise to see $90.7 \%$ of participants vote yes in using emojis and other inserts. While the other 9.3\% (19 participants; 9 from India, 10 from the United States) said they do not. The second question reflects that $74.5 \%$ of survey-takers (152 participants; 69 from the United States, 75 from India, 8 other) stated that they do think of grammar rules and punctuation while texting. 25.5\% (52 participants; 29 from the United States, 23 from India) said they do not. It may be easier to answer yes since a majority of smartphones and computers automatically mention if there is a spelling error, grammar issue, or punctuation missing. The third question projects that $61.8 \%$ of participants do not post personal information on social media, this was the answer for 126 people (77 from the United States, 46 from India, 3 Other). It is not a surprise that many have voted no since many people may be more inclined not to post confidential and personal information online. Many would keep their profiles private rather than public. In contrast, $38.2 \%$ do post 
personal information on social media (78 participants; 52 from India, 21 from the United States, 5 Other). Lastly, the fourth question, explains how out of 204 responses, 192 participants (91 from United States, 91 from India, 10 from other), that means almost $95 \%$ of the respondents think that social media is a major form of communication. This is no shock as most communication in today's day, and age is done through social media. With Twitter ${ }^{\mathrm{TM}}$, Facebook, Instagram, Snapchat, etc., communicating with someone from across the world is easier than ever before.
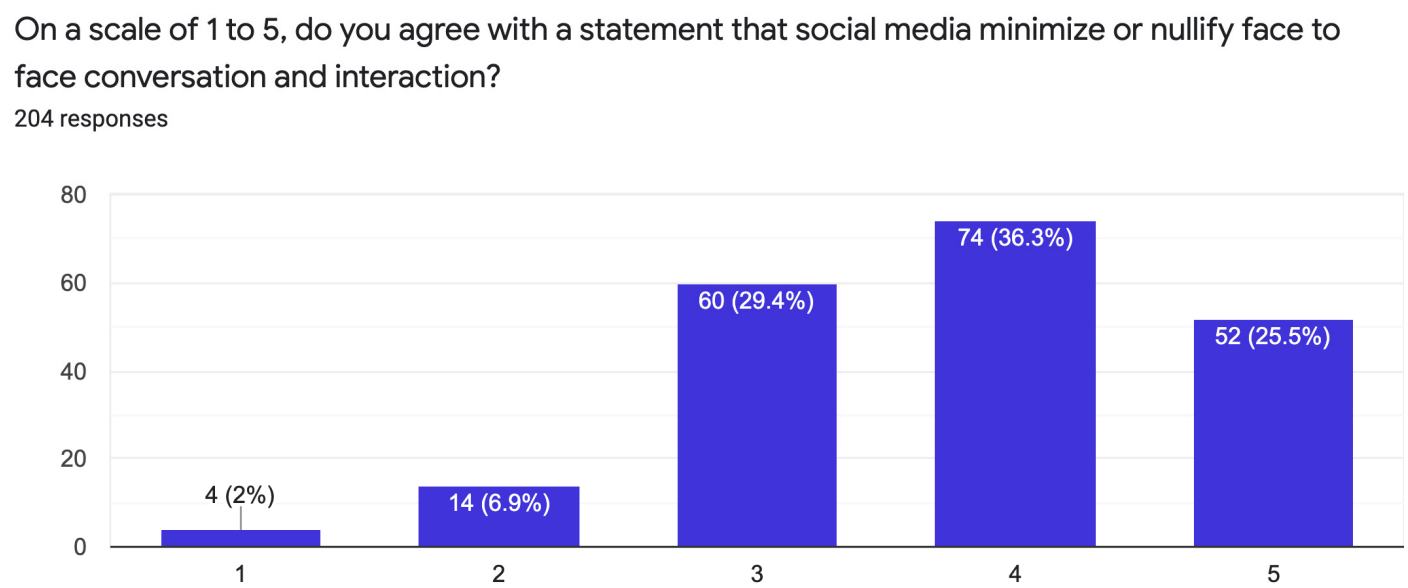

Figure 3. On a scale of 1 to 5 , do you agree with a statement that social media minimize or nullify face to face conversation and interaction?

Figure $3,25.5 \%$ of the participants strongly agreed that social media minimize or nullify face to face conversation and interaction. while just $2 \%$ believe that social media does not really impact that much. The largest percentage, $36.3 \%$, (74 participants), agreed. And lastly, 29.4\% (60 people) neither agree or disagree.
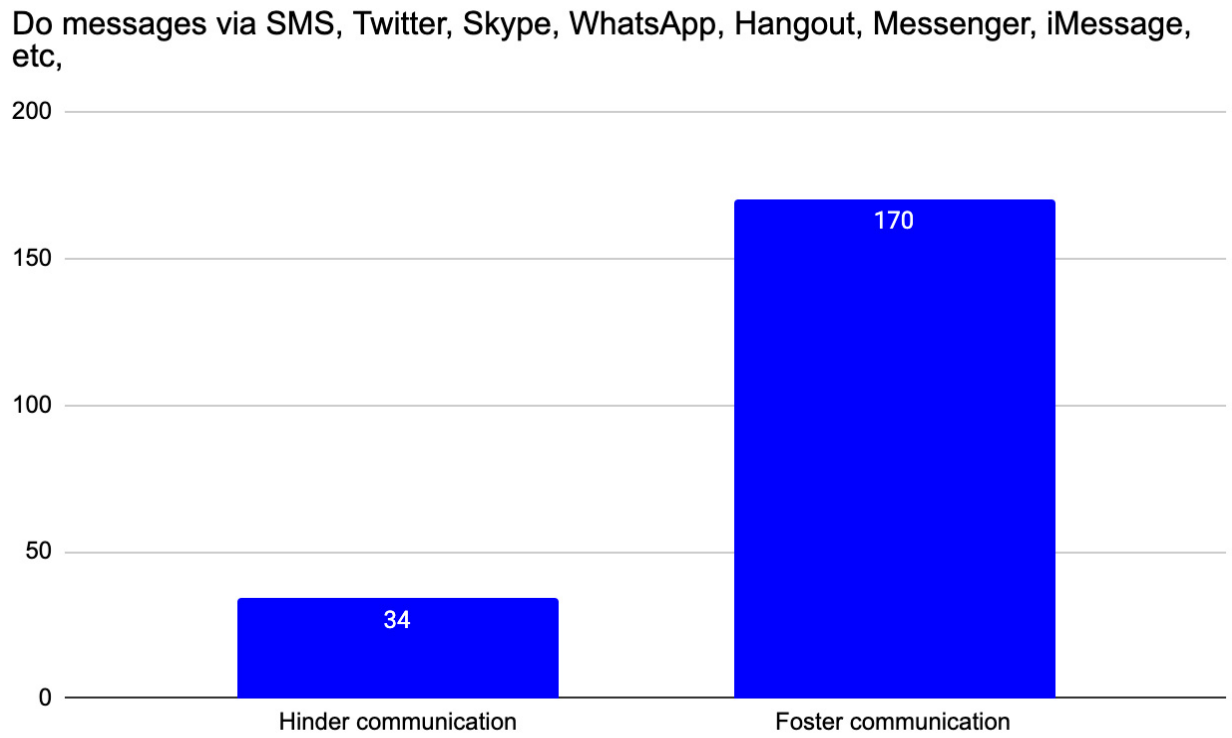

Figure 4. Do messages via SMS, Twitter ${ }^{\mathrm{TM}}$, Skype ${ }^{\mathrm{TM}}$, WhatsApp ${ }^{\mathrm{TM}}$, Hangout ${ }^{\mathrm{TM}}$, Messenger ${ }^{\mathrm{TM}}$, iMessage, etc: hinder communication or foster communication? 
From Figure 4, 83.3\% of participants ( 82 from India, 76 from the United States) think that social media platforms foster communication that is messaging via SMS, Twitter ${ }^{\mathrm{TM}}$, Skype ${ }^{\mathrm{TM}}$, WhatsApp ${ }^{\mathrm{TM}}$, Hangout ${ }^{\mathrm{TM}}$, Messenger ${ }^{\mathrm{TM}}$, iMessage $^{\mathrm{TM}}$. While the rest $16.67 \%$ think that social media hinders their communication (18 participants from the United States, 15 from India). It is no surprise and quite clear that many participants of the survey agree that messages via social media platforms such as Twitter ${ }^{\mathrm{TM}}$ and Messenger ${ }^{\mathrm{TM}}$ foster communication. With the use of online media, it is easier to reach someone on the other side of the world. Therefore, making it easier to communicate with one another.

\subsection{Survey Long Answer Questions:}

Do you notice yourself using internet lingo or slang from social media? If so, which ones and how? If not, please explain why not.

The participants expressed mixed emotions for this survey question. The majority of the 204 participants mentioned that they noticed themselves using internet lingo or slang from social media. They also stated that social media has changed how they communicate with their friends, relatives, and colleagues. Many stated they use various abbreviations and slang from social media. Popular abbreviations and slang that participants mentioned included FYI, LOL, TBT, LMAO, NP, IDK, and BTW. With this in mind, it showcases how social media has affected how certain age groups communicate and how specific internet slang has become part of people's everyday conversations. Furthermore, the survey takers mentioned how they would follow what is trending on social media such as phrases or lingo that can be found on Twitter ${ }^{\mathrm{TM}}$ or TikTok ${ }^{\mathrm{TM}}$. On the other end, those participants who do not use slang and internet lingo explained the reasons for not doing so. One participant mentioned that they liked keeping communication "simple and effective" and that it "should be more understandable to for anyone" therefore this person does not really use slang or internet lingo. Another participant explained that "because I am still more comfortable and accustomed to how I would "normally" speak and not influenced by social media lingo or slang". With this information, it is understandable that many people are not using social media lingo when speaking as well. Some also thought their abbreviations could be taken in multiple meanings and did not want their messages to be misunderstood and unclear to others.

How do you think social media is affecting our verbal and written communications? Please explain how.

Participants have expressed how social media is affecting verbal and written communications. Many participants praised social media and the change it has presented. For instance, one survey taker mentioned that they were extremely limited in interacting with others before social media. They had to wait for a letter in the mail and wait a week to get pictures developed. Now it is easier to communicate with others with the help of social media. Another participant mentioned how it helps an introvert to express themselves and that they are more comfortable talking via social media. One response said how social media "makes language more colorful and easier to understand". However, there were also contrasting opinions on the effect of social media on verbal and written communication. For example, one survey taker mentioned that many might "neglect to focus our inner feelings and emotions... missed the importance of creating a story through writing to give details and life of each stories" while another mentioned that "it normalizes a system that immediately delivers ideas to others without authentication or self-criticism". Furthermore, others were also concerned with the degrading of the grammar, and fewer spelling rules. Simultaneously, texting is also used accidentally during academic and professional writings. Due to short forms of words and phrases, abbreviations, and slang many people are losing proper vocabulary. Moreover, because of social media, the change enhances people to disregard grammar rules and often forget to correct punctuations. Alongside were some impressive statements shared by our audience such as: "we speak the way we type," "sentence loses the essence of it," "I think social media shapes our humor a lot." On the other hand, people felt the detachment with their close ones, "verbal communication is mostly affected by people just texting one another and not feeling the need to call." With this in mind, the change in communication is evident.

In what ways is social media influencing the way we communicate? Please provide examples.

As mentioned by one participant for this question, "communication has become multi-faceted". Many responses to this question agreed that social media has a great influence on communication and explained the various ways in which it has done so. For instance, because social media allows interaction with others and an ability to share opinions with numerous listeners and viewers. Nowadays, people can interact with others without censorship on what a person wants to express. Social media has helped people become more confident when talking about different topics which they are not in-person, they are now able to share their thoughts and opinions on everything, which can also be done anonymously. Keeping in mind the degree of usage of the internet and social media and studying how much it influences people around the world that connects them, nowadays politicians, influences, businesses use Instagram ${ }^{\mathrm{TM}}$, Facebook ${ }^{\mathrm{TM}}$, Twitter ${ }^{\mathrm{TM}}$ just to express their thoughts regarding what is happening to 
our world, and also project their work. As discussed, social media enhances the way people communicate because of how it has become a more and more efficient and cost-effective way to talk to people across the globe while also opening up doors to discover another person's culture. Social media platforms such as Twitter ${ }^{\mathrm{TM}}$, Instagram ${ }^{\mathrm{TM}}$, and TikTok $^{\mathrm{TM}}$ offer multiple methods for people to share their thoughts and ideas, which in return enables and creates fuel for more conversations. Distinct apps like Facetime ${ }^{\mathrm{TM}}$, Snapchat ${ }^{\mathrm{TM}}$, Skype ${ }^{\mathrm{TM}}$, Zoom ${ }^{\mathrm{TM}}$, and Facebook Messenger ${ }^{\mathrm{TM}}$ allow face-to-face communication from anywhere in the world. The survey's long answer emphasizes various answers such as how social media makes "communicating with others much more accessible". Another answer stated that the use of "social media has really opened many creative blogging and different contents that you would not see on television. Bloggers are a new way of communicating your creative ideas and thinking". Furthermore, it has enabled "better communication of feelings through emoticons and gifs. It is also helping the brands to communicate their products to customers through affiliate marketing giving them the better reach and influencing people to buy their products". Simultaneously, with an increase in the use of social media with communication, the criticism has also increased, especially on what people post, share, comment. For instance, one survey taker mentioned how social media has also "hinder deep meaningful connections" and another stated that "we are losing our patience in real life because of habit of instant gratification". The use of social media, "decreases need for face-to-face social interactions hence less social skills".

\section{Discussion}

This research paper's main focus was to understand how social media influences the way people communicate; whether it is by how people speak or how people type or text each other. There were various ways in which social media has influenced how people communicate. The use of secondary sources such as the survey from real participants about their experience, goes to show how social media does have a great influence on the way people communicate. As mentioned previously, this research study builds on the research journal called "Impact Of Social Media On Interpersonal Communication Patterns" by Velga Vevere. This paper also used six social media questions adapted from it to help create validity for the survey. In comparison to the study that was conducted in that research journal, the results from this research paper achieved significant similarities in terms of answers received. Though, one major difference was the question that asked if participants posted personal information on social media. In Vevere's research many stated that they do post personal information, but in this research 126 participants chose to answer no in their response. This should not come off as a surprise for today's participants because many people may be more inclined not to post confidential and personal information online. Many would keep their profiles private rather than public. To continue with understanding how social media has influenced the way people communicate. Therefore, after inferring the results of the survey, there are both pros and cons that social media has on the influence of social media. The pros are that it is easier to gain more information and knowledge about a subject. Two people can infer about a topic online. Another pro is that social media has become more accessible to connect with people who are unable to see each other from across the globe. Lastly, social media has a great influence on fueling conversations. Many people use emoticons, emojis, abbreviations, and internet lingo to communicate with one another. This makes it more personal and intimate for people as well. This research's deductions hold great similarities to Vevere's since hers mentioned how "the theme of communication in philosophy acquires a special importance during the 20th and 21st centuries due to the development of new technologies and advance of social networking. This changes the whole dynamics of situation, since social media presupposes interactivity, reciprocity, involvement. At the same time, the negative factors also come forth - the loss of privacy, the over communicativeness, social alienation, dependency issues" (Vevere, 2015). This can relate to the cons of the influence on social media since there is more improper grammar, a reluctance for face-to-face conversion which lessens social skills and hinders deeper connections between people. During this research, there were some implications that occurred during the research. The survey was only sent to family and friends in the United States and India, and therefore does not represent the whole population. This survey would need to be answered by everyone in the whole world to get a more generalized answer. Another implication is that some of the survey questions were worded similarly so answers may be too broad. With all of these ideas and perspectives in mind, it is no wonder as to how social media has greatly influenced and impacted the way in which people communicate.

\section{Conclusion}

The overall research on how social media is influencing the way people communicate is important to understand because of the change it has presented. From the new and shortened form of words, phrases, and abbreviations in people's messages to people being more comfortable speaking online than in person. The change that social media has brought forth to communication is evident and noticeable. Social media has been changing in the past few years. It has impacted the way in which people communicate in more ways than ever before. Therefore, with this 
study about the influence on social media and communication, it truly showcases the ways in which it has been able to do so and will continue to do so in the future.

\section{References}

Baruah, T. D. (2012). Effectiveness of Social Media as a tool of communication and its potential for technology enabled connections: A micro-level study. International Journal of Scientific Research Publications, 2(5), 1-10. Retrieved from http://www.ijsrp.org/research_paper_may2012/rp24.html

Jha, S., \& Gulla, A. (n.d.). Interpersonal Communication in the Age of Social Media. Review of Management, 9(3-4), 5-8. $\quad$ Retrieved from https://www.researchgate.net/publication/343473353_Interpersonal_Communication_in_the_Age_of_Socia 1_Media

Kolb, B. (2018). Marketing Research: A Concise Introduction (2nd ed.). Sage Publications.

Othman, W., Fariha, Z., \& Ngah, N. (2016). The uses of Social Media on Student's Communication and Self Concepts among TATIUC Students. Indian Journal of Science and Technology, 9(17), 1-8, https://doi.org/10.17485/ijst/2016/v9i17/88730

Owusu-Acheaw, M., \& Larson, A. (2015). Use of Social Media and its Impact on Academic Performance of Tertiary Institution Students: A Study of Students of Koforidua Polytechnic. Ghana', Journal of Education and Practice, 6(6), 94-101. Retrieved from https://www.iiste.org/Journals/index.php/JEP/article/view/20048

Sampling methods|Types and techniques explained. (2020, June 19). Retrieved from https://www.scribbr.com/methodology/sampling-methods/

Siddiqui, S., \& Singh, T. (2016). Social media its impact with positive and negative aspects. International Journal of Computer Applications Technology and Research, 5(2), 71-75. https://doi.org/10.7753/IJCATR0502.1006

Social media effects on communication. (2020, March 31). Retrieved from https://www.uopeople.edu/blog/how-social-media-affected-communication/

Sponcil, M., \& Gitimu, P. (2012). Use of social media by college students: Relationship to communication and self-concept. Journal of Technology Research, 4, 1-13. Retrieved from https://www.researchgate.net/publication/266344276_Use_of_social_media_by_college_students_Relations hip_to_communication_and_self-concept

Subramanian, K. (2017). Influence of Social Media in Interpersonal Communication. International Journal of Scientific Progress and Research (IJSPR), 38(109), 70-75. Retrieved from https://www.ijspr.com/citations/v38n2/IJSPR_3802_2069.pdf

Vevere, V. (2015). Impact of Social Media on Interpersonal Communication Patterns. Societal Studies, 7(1), 124-138. https://doi.org/10.13165/SMS-15-7-1-09

\section{Appendix A}

\section{Survey Questions}

Demographics

1) Gender
( ) Female
() Male

2) Age

( ) $15-20$

( ) 21-25

( ) $26-30$

( ) 31-35

( ) $36+$

3) Ethnicity

( ) Asian 
( ) Black or African American

( ) Native American or Alaskan Native

() White or Caucasian

( ) Native Hawaiian or Pacific Islander

() Hispanic or Latino

( ) Prefer not to say

4) Location

( ) United States

() India

( ) Prefer not to say

5) Education

( ) High School

( ) Bachelor's Degree

( ) Master's Degree

( ) Doctorate Degree

() Other

Social Media Questions

1) Which social media platform (s) do you use to communicate with others?

( ) Facebook

() Instagram

() Snapchat

( ) Twitter

() WhatsApp

() Other

2) Do you think that social media influences the way we speak and write in our everyday lives?

( ) Strongly Agree

() Agree

( ) Neither Agree or disagree

() Disagree

( ) Strongly Disagree

3) Do you use emojis or other inserts when writing text messages or direct messages?

( ) Yes

( ) No

4) When text messaging do you think of the grammar rules and punctuation?

( ) Yes

( ) No

5) Do you post personal information on social media?

( ) Yes

( ) No

6) On a scale of 1 to 5 , do you agree with a statement that social media minimize or nullify face to face conversation and interaction?

Strongly Disagree ( ) 1 ( ) 2 ( ) 3 ( ) 4 ( ) 5 Strongly Agree

7) Do messages via SMS, Twitter ${ }^{\mathrm{TM}}$, Skype $^{\mathrm{TM}}$, WhatsApp ${ }^{\mathrm{TM}}$, Hangout ${ }^{\mathrm{TM}}$, Messenger $^{\mathrm{TM}}$, iMessage ${ }^{\mathrm{TM}}$, etc foster or 
hinder communication?

( ) Foster communication

( ) Hinder communication

8) Whether social media is a major form of communication tool?

( ) Yes

() No

9) Do you notice yourself using internet lingo or slang from social media? If so, which ones and how? If not, please explain why not.

10) How do you think social media is affecting our verbal and written communications? Please explain how.

11) In what ways is social media influencing the way we communicate? Please provide examples.

\section{Copyrights}

Copyright for this article is retained by the author, with first publication rights granted to the journal.

This is an open-access article distributed under the terms and conditions of the Creative Commons Attribution license (http://creativecommons.org/licenses/by/4.0/). 